\title{
A Case of Supernumerary Kidney
}

Marco Mejia ${ }^{1}$, Joseph Limback ${ }^{2}$, Ashley Ramirez ${ }^{2}$, Jeremy R. Burt ${ }^{2}$

1. Radiology, University of Central Florida College of Medicine, Orlando, USA 2. Radiology, Florida Hospital, Orlando, USA

Corresponding author: Joseph Limback, joseph.limback.md@flhosp.org

\section{Abstract}

A supernumerary kidney is extremely rare, with less than 100 cases currently reported in the literature. When this variant is present, the additional renal parenchyma demonstrates its own collecting system, vascular supply, and distinct encapsulated parenchyma. Herein, we discuss the case of a supernumerary kidney in a 20-year-old male.

Categories: Radiology, Urology, Nephrology

Keywords: crossed fused ectopia, supernumerary kidney, congenital kidney

\section{Introduction}

A supernumerary kidney is one of the rarest congenital anomalies of the urogenital system. There are currently less than 100 cases currently reported in the literature, with the first case being described in 1965 [1]. This anatomic variation is said to occur whenever there are more than two kidneys present, with the additional kidney having its own collecting system, vascular supply, and distinct encapsulated parenchyma. We report a rare case of a fused supernumerary kidney in a 20 -year-old male patient.

\section{Case Presentation}

A 20 -year-old male with a past medical history of seizures since the age of 14 and treated with divalproex sodium and topiramate presented to the emergency department with right lower quadrant abdominal pain. On presentation, all vital signs appeared normal. A complete metabolic panel and blood count were within normal limits (creatinine of $0.89 \mathrm{mg} / \mathrm{dL}$ and blood urea nitrogen of $14 \mathrm{mg} / \mathrm{dL}$ ). An abdominal ultrasound was performed that demonstrated a nonspecific structure in the right lower abdomen with a vascular fatty central parenchyma, as well as an avascular hypoechoic peripheral parenchyma (Figures 1,2).

\footnotetext{
Received 11/08/2018

Review began 11/29/2018

Review ended 11/30/2018

Published 12/05/2018

๑) Copyright 2018

Mejia et al. This is an open access article

distributed under the terms of the

Creative Commons Attribution License

CC-BY 3.0., which permits unrestricted

use, distribution, and reproduction in any

medium, provided the original author and source are credited.
} 


\section{Cureus}

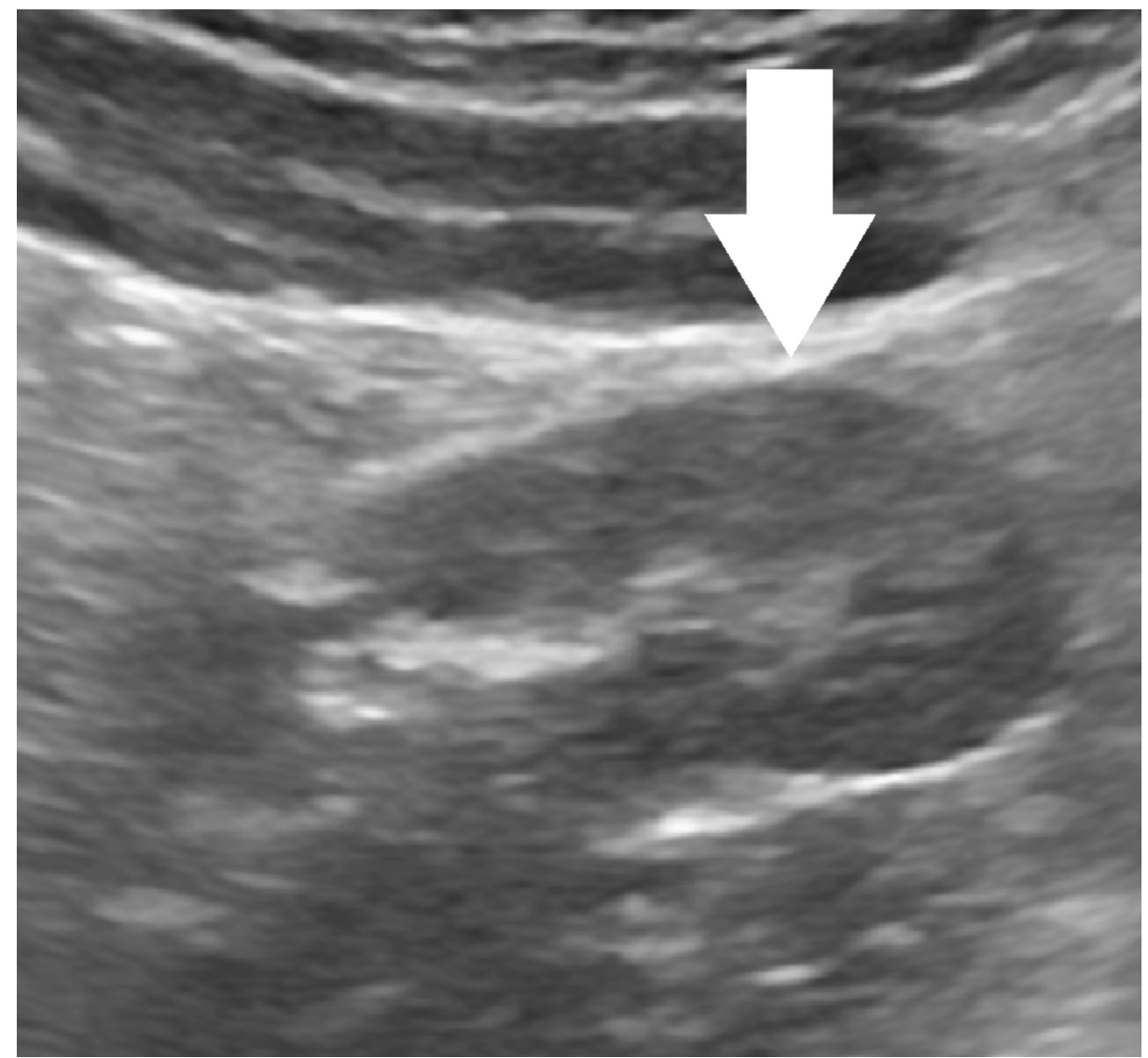

\section{FIGURE 1: Grayscale Ultrasound Image}

Grayscale ultrasound image demonstrating a centrally hyperechoic and peripherally hypoechoic right lower quadrant mass without signs of inflammation. 


\section{Cureus}

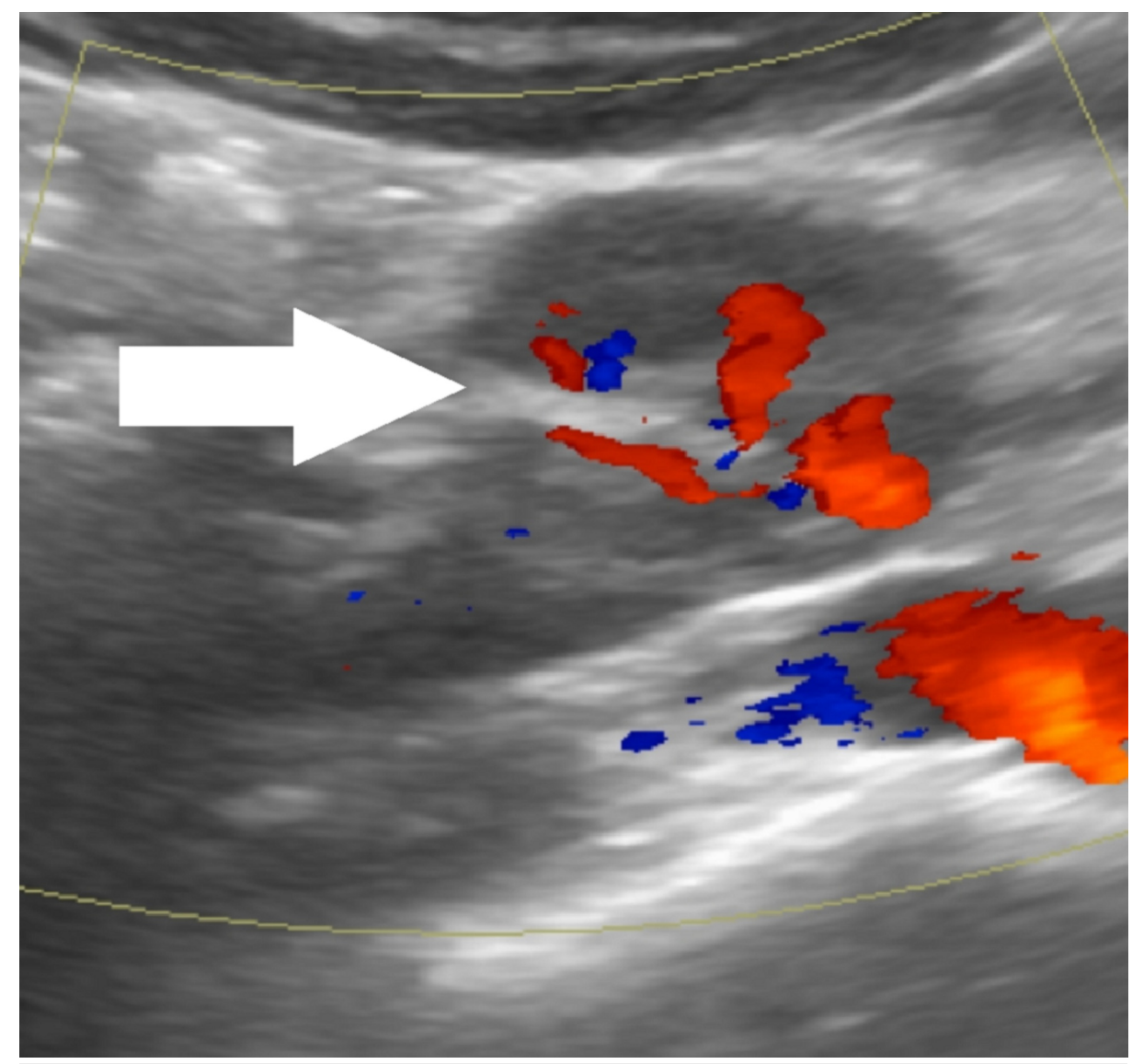

FIGURE 2: Doppler Ultrasound Image Demonstrating a Vascular Pedicle

Doppler ultrasound image demonstrating the reniform appearance of the mass with a central vascular pedicle.

There were no acute findings on ultrasound. A computed tomography (CT) scan demonstrated no acute abnormality, but a supernumerary kidney fused to the lower pole of the native right kidney was visualized (Figures 3, 4). 


\section{Cureus}

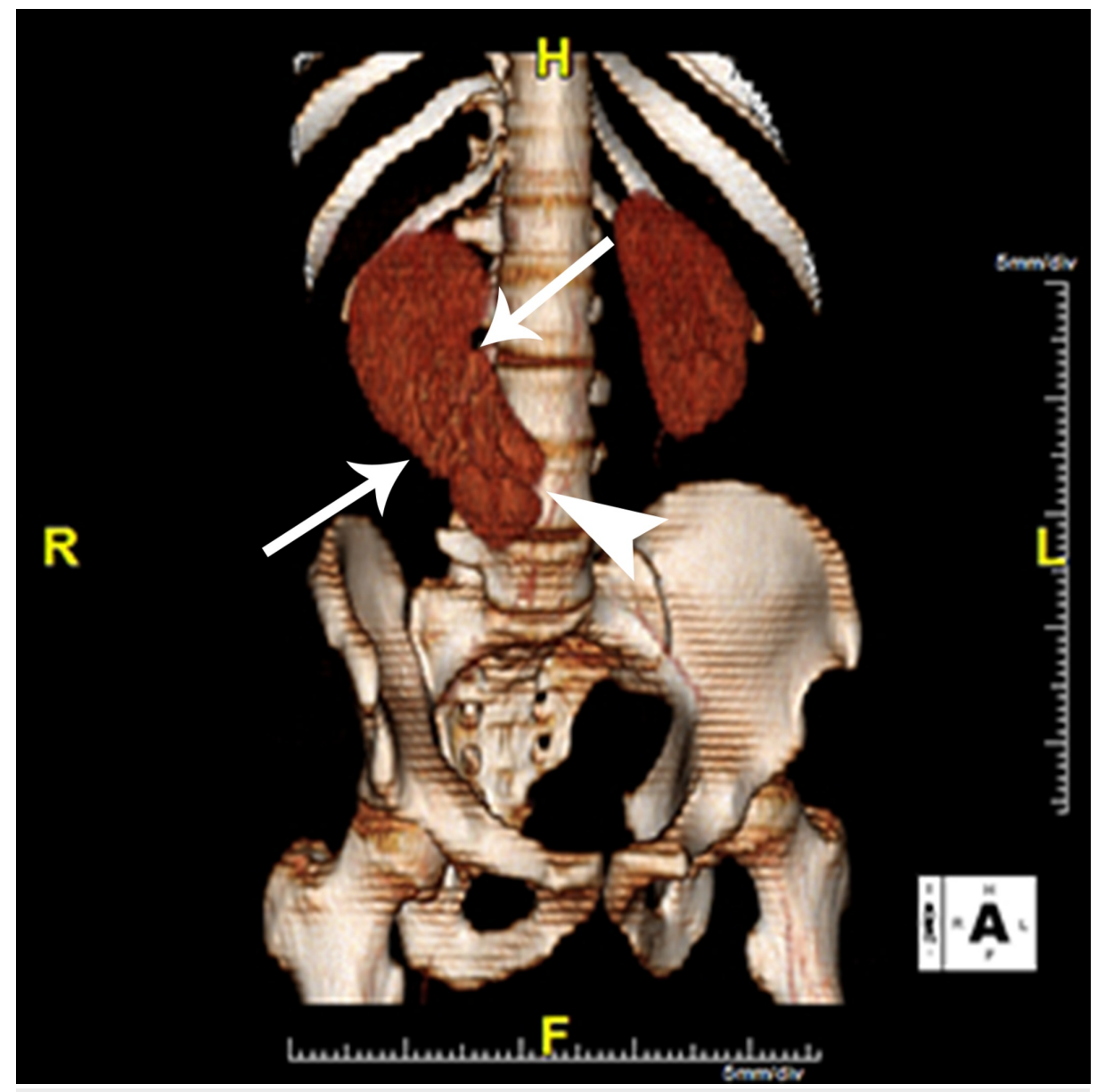

FIGURE 3: 3D Computed Tomography (CT) Reconstruction

Three-dimensional (3D) reconstructed CT image of the kidneys demonstrates bilateral native kidneys, as well as an ectopic supernumerary kidney fused to the lower pole of the native right kidney (white arrows). The image also demonstrates the supernumerary kidney hilum (white arrowhead). 


\section{Cureus}

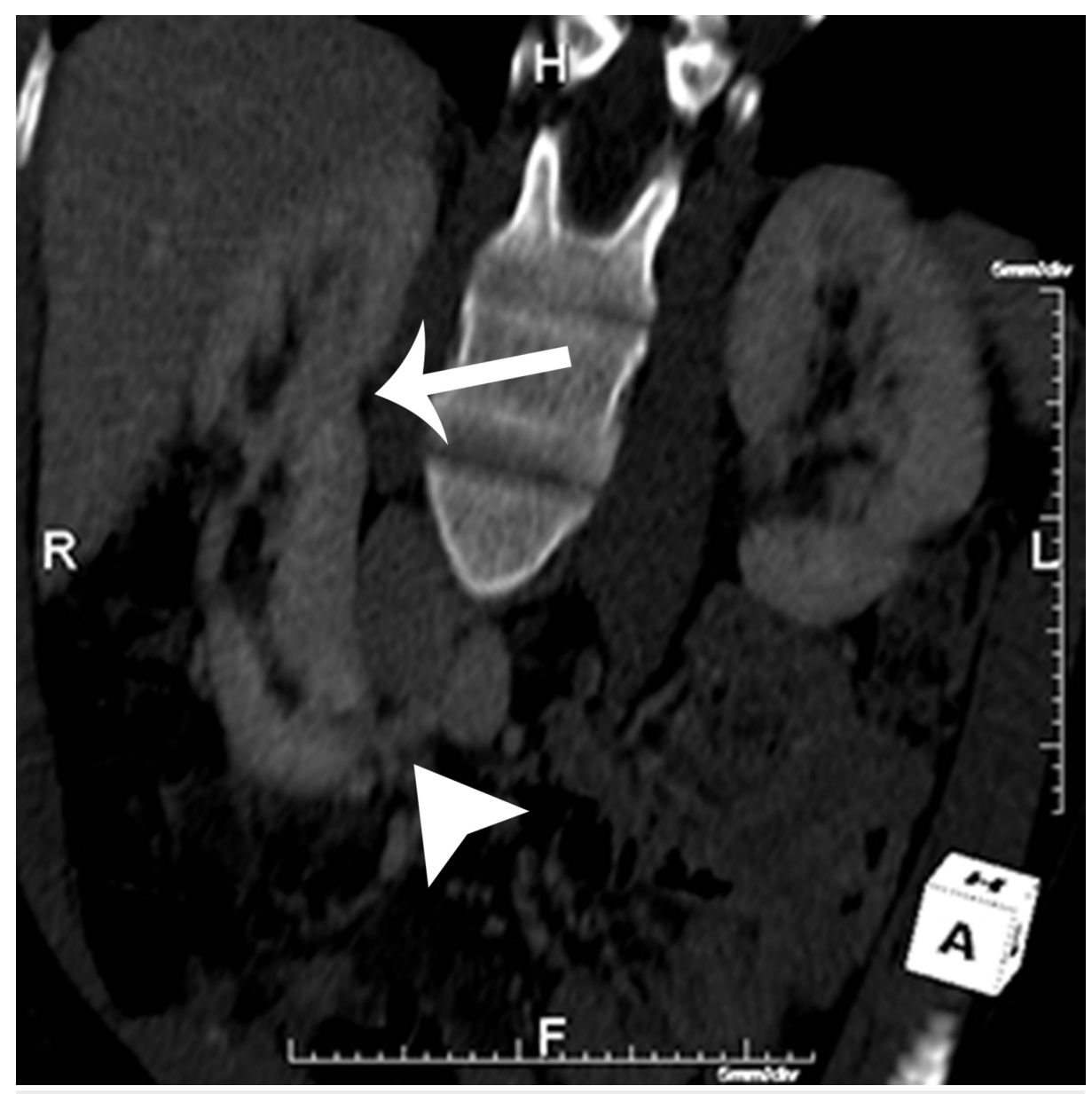

FIGURE 4: Coronal Oblique CT Reconstruction

Coronal oblique reconstructed computed tomography (CT) image of the kidneys demonstrates bilateral native kidneys, as well as an ectopic supernumerary kidney fused to the lower pole of the native right kidney (white arrows). Additionally, the supernumerary kidney renal vein can be seen draining into the inferior vena cava (white arrowhead).

\section{Discussion}

The supernumerary kidney is an extremely rare congenital anomaly, with less than 100 cases being reported in the literature [1]. This condition is asymptomatic in most cases but, when symptomatic, it most often presents with symptoms in the fourth decade of life. The most commonly reported symptoms are pain, a palpable abdominal mass, and fever [2-3]. Some cases may also present with urinary symptoms, such as urinary incontinence [4]. The diagnosis is made with imaging, which may include computed tomography (CT), magnetic resonance imaging (MRI), or ultrasonography.

Most cases of supernumerary kidney present with one additional kidney. The additional kidney most commonly occurs ipsilateral and caudal to the left kidney, with the supernumerary kidney being smaller than the native kidney [3]. The supernumerary kidney is thought to arise from an abnormal division of the nephrogenic cord into two separate metanephric blastemas during the fifth to seventh week of gestation [5]. This process yields two kidneys with partial or duplicated ureteral buds which may eventually lead to the formation of an accessory kidney. These can occur with two separate collecting systems or as a partially duplicated system where one ureter drains into the other. In even rarer cases, supernumerary kidneys have been reported to occur with an ectopic ureter that drains into other structures, such as the vagina [6]. These cases will present with urinary incontinence.

Although there is a very low incidence of supernumerary kidney, associated congenital abnormalities have been reported. These include horseshoe kidney malformation, ventricular septal defects, neural tube defects, and cloacal abnormalities, such as urethral atresia, vaginal atresia, ectopic ureter implantation, imperforate anus, and duplication of urethra penis and urethra [7-8].

\section{Conclusions}


Supernumerary kidneys are extremely rare. This case is even more unique in two regards. First, the supernumerary kidney is located on the right. Second, the supernumerary kidney is fused to the lower pole of the native kidney. Our patient did not exhibit associated congenital abnormalities. However, his unexplained right lower quadrant pain could be due to his anatomic variation with the known associated symptom of pain. At the time of writing this article, the patient had not received any intervention due to the lack of acute findings.

\section{Additional Information}

\section{Disclosures}

Human subjects: Consent was obtained by all participants in this study. issued approval . . Conflicts of interest: In compliance with the ICMJE uniform disclosure form, all authors declare the following: Payment/services info: All authors have declared that no financial support was received from any organization for the submitted work. Financial relationships: All authors have declared that they have no financial relationships at present or within the previous three years with any organizations that might have an interest in the submitted work. Other relationships: All authors have declared that there are no other relationships or activities that could appear to have influenced the submitted work.

\section{Acknowledgements}

This material is the result of work supported with resources and the use of facilities at Florida Hospital. Additionally, we would like to thank Tamma Rinderknecht, RDMS for her help in the discovery and documentation of this case.

\section{References}

1. Sureka B, Mittal MK, Mittal A, Sinha M, Thukral BB: Supernumerary kidneys--a rare anatomic variant . Surg Radiol Anat. 2014, 36:199-202. 10.1007/s00276-013-1135-Z

2. Sen V, Bozkurt IH, Yonguc T, Aydogdu O, Basmaci I: A rare case of supernumerary fused and malrotated kidney. Int Braz J Urol. 2017, 43:561-62. 10.1590/S1677-5538.IBJU.2015.0420

3. Jamshidian H, Tavakoli K, Salahshour F, Nabighadim A, Amini E: Supernumerary kidney associated with horseshoe malformation: a case report and review of literature. Urol Case Rep. 2017, 11:57-59. 10.1016/j.eucr.2016.11.010

4. Suresh J, Gnanasekaran N, Dev B: Fused supernumerary kidney. Radiol Case Rep. 2011, 6:552. 10.2484/rcr.v6i4.552

5. N'Guessan G, Stephens FD: Supernumerary kidney. J Urol. 1983, 130:649-53. 10.1016/S0022-5347(17)513853

6. Gonzalvo Pérez V, Ramada Benlloch F, Blasco Alfonso JE, Donderis Guastavino C, Navalón Verdejo P, Zaragoza Orts J: Supernumerary kidney with ectopic ureteral opening to the vagina associated with horseshoe kidney (Article in Spanish). Actas Urol Esp. 1992, 16:796-98.

7. Unal M, Erem C, Serçe K, Tuncer C, Bostan M, Gökçe M: The presence of both horseshoe and a supernumerary kidney associated with coarctation of aorta. Acta Cardiol. 1995, 50:155-60.

8. Antony J: Complete duplication of female urethra with vaginal atresia and supernumerary kidney . J Urol. 1977, 118:877-78. 10.1016/S0022-5347(17)58231-2 